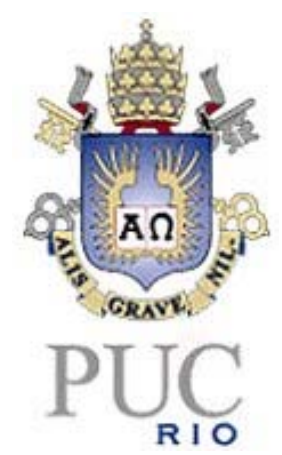

Sergio León Montoya Castillo

\title{
Modelagem do Comportamento Estático e Sísmico da Barragem de Terra de Pomacocha- Peru
}

Dissertação de Mestrado

Dissertação apresentada como requisito parcial para obtenção do título de Mestre pelo Programa de PósGraduação em Engenharia Civil da PUC-Rio.Área de Concentração: Geotecnia

Orientador: Prof. Celso Romanel

Rio de Janeiro

Abril de 2003 


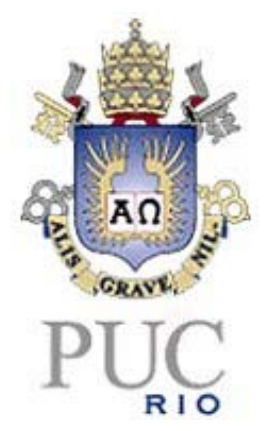

Sergio León Montoya Castillo

\title{
Modelagem do Comportamento Estático e Sísmico da Barragem de Terra de Pomacocha- Peru
}

\begin{abstract}
Dissertação apresentada como requisito parcial para obtenção do título de Mestre pelo Programa de PósGraduação em Engenharia Civil da PUC-Rio. Aprovada pela Comissão Examinadora abaixo assinada.
\end{abstract}

\author{
Prof. Celso Romanel \\ Orientador \\ PUC-Rio
}

Profa Bernadete Ragoni Danziger

Universidade Federal Fluminense

Profa Deane de Mesquita Roehl

PUC-Rio

Prof Ney Augusto Dumont

Coordenador Setorial do Centro

Técnico Científico - PUC-Rio

Rio de Janeiro, abril de 2003 
Todos os direitos reservados. É proibida a reprodução total ou parcial do trabalho sem autorização da universidade, do autor e do orientador.

\section{Sergio Léon Montoya Castillo}

Graduou-se em Engenharia Civil pela Universidade Nacional de Colômbia em 1993. Exerceu diversas atividades em áreas da engenharia civil, nos setores público e privado. Atuou como Secretário de Obras e de Serviços Públicos do Município de Girardota, Colômbia

Ficha Catalográfica

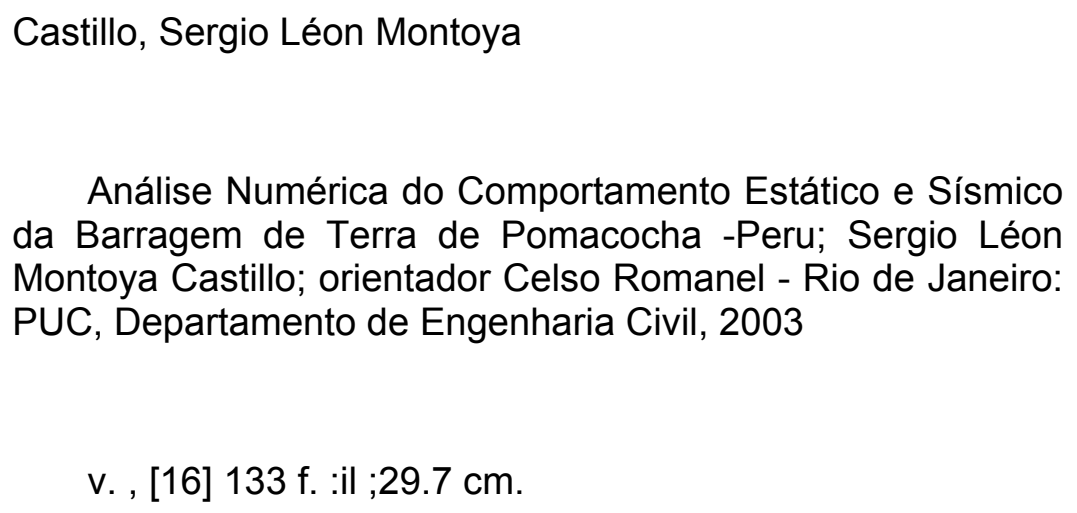

Análise Numérica do Comportamento Estático e Sísmico da Barragem de Terra de Pomacocha -Peru; Sergio Léon Montoya Castillo; orientador Celso Romanel - Rio de Janeiro: PUC, Departamento de Engenharia Civil, 2003

v. , [16] 133 f. :il ;29.7 cm.

1. Dissertação (mestrado) - Pontifícia Universidade Católica do Rio de Janeiro, Departamento de Engenharia Civil

Incluí referências bibliográficas.

1. Engenharia Civil - Teses. 2. Modelagem numérica. 3. Barragem de terra. 4. Análise estática e sísmica. 5. ABAQUS. 6. Elementos finitos. I. Romanel, Celso. II. Pontifícia Universidade Católica do Rio de Janeiro. Departamento de Engenharia Civil. III. Titulo 
À minha esposa Maria Cristina (La Tancha) por sua paciência, amor e compreensão; à minha mãe e ao meu pai, pelos valores morais de amor e respeito, ensinados durante minha vida; aos meus irmãos Diego, Felipe e Jorge 


\section{Agradecimentos}

Desejo expressar minha gratidão ao professor Celso Romanel pela orientação no desenvolvimento deste trabalho.

Ao povo brasileiro, e à Capes em particular, pela concessão da bolsa de estudos que me permitiu a realização do curso.

A todos os professores do Departamento de Engenharia Civil da PUC-Rio, pelos conhecimentos técnicos transmitidos nas várias disciplinas que freqüentei.

À querida e estimada secretária Ana Roxo por sua disponibilidade em oferecer informações, conselhos e sugestões aos alunos do programa e, em especial, a nosotros, alunos estrangeiros.

À minha esposa, mais uma vez, por ter me incentivado a seguir estudos de pósgraduação.

À minha família pelo apoio, ainda que distante, mas sempre firme, forte e em mim presente.

À professora Deane pela colaboração neste trabalho.

A todos os meus colegas do curso de mestrado em Engenharia Civil da PUCRio pela convivência, amizade e ensino informal da língua portuguesa.

Aos funcionários da Biblioteca Setorial do CTC, em especial à Suzy, Diógenes, Alexandre e Flávio.

A Deus porque sem ajuda Dele muitas coisas seriam impossíveis. 


\section{Resumo}

Castillo, Sergio Léon Montoya, Romanel, Celso Modelagem do Comportamento Estático e Sísmico da Barragem de Terra de Pomacocha- Peru. Rio de Janeiro, 2003. 133p. Dissertação de Mestrado Departamento de Engenharia Civil, Pontifícia Universidade Católica do Rio de Janeiro.

Construção de barragens de terra é uma atividade milenar, empregada com o objetivo de atender às mais diversas necessidades humanas como o armazenamento de água, irrigação, regularização de cursos d'água, geração de energia elétrica, etc. Ao longo da história, o projeto destas obras de terra passou de conceitos simples, baseados em técnicas empíricas e regras intuitivas, para as análises modernas que consideram o comportamento da barragem em suas diversas fases de vida (construção, enchimento do reservatório, regime de plena operação), sob carregamentos estáticos e sísmicos, condições de contorno complexas e sofisticadas relações constitutivas dos materiais da estrutura e do maciço de fundação. Neste trabalho a construção, primeiro enchimento do reservatório e a resposta sísmica da barragem de terra de Pomacocha, Peru, são analisados pelo método dos elementos finitos, utilizando o "software" ABAQUS (versão 6.3). Os campos de tensão e de deslocamentos para diversos estágios de aplicação dos carregamentos estático e sísmico são apresentados, incluindo-se histórias de deformação e de tensão para determinados pontos do corpo da barragem e do solo de fundação.

\section{Palavras-chave}

Modelagem numérica; barragem de terra; análise estática e sísmica; ABAQUS; elementos finitos 


\section{Abstract}

Castillo, Sergio Léon Montoya, Romanel, Celso (advisor). Numerical Analysis of the Static and Seismic Behavior of Pomacocha Dam - Peru. Rio de Janeiro, 2003. 133p. MSc Dissertation - Department of Civil Engineering, Pontifícia Universidade Católica do Rio de Janeiro

Dam construction is a millenary activity, carried out with the objective of fulfilling human necessities as water supply, land irrigation, water flow regularization, electric power generation, etc. Along the history, the design of these earthworks evolved from simple concepts, based on empirical techniques and rules of thumb, to modern analyses that consider all phases of a dam's life (construction, first reservoir filling, full operation) under static and seismic loads, as well as complex boundary conditions and sophisticated constitutive relationships for the structure itself and the foundation mass. In this work, the construction, first reservoir filling and the seismic response of the Pomacocha Dam, located in Peru, are analyzed by the finite element method using the software ABAQUS (version 6.2). At several loading stages the corresponding stress and displacement fields are presented as well as, for some specific points in the dam body and in the foundation soil, the characteristic stress and strain histories during the static and seismic loads.

\section{Keywords}

Numerical modeling; earth dam; static and seismic analysis; ABAQUS; finite elements 


\section{Sumário}

1 INTRODUÇÃO

2. REVISÃO BIBLIOGRÁFICA 20

2.1. Comportamento durante a construção 20

2.1.1. Distribuição dos recalques 20

2.1.2 Influencia de anisotropia 22

2.1.3. Transferência de cargas 22

2.1.4. Trajetórias de tensões na construção 25

2.2. Comportamento durante o primeiro enchimento do reservatório 26

2.2.1. Efeitos do primeiro enchimento em barragem zonada 27

2.2.2. Trajetórias de tensões no primeiro enchimento 28

2.3. Comportamento durante o carregamento sísmico 30

2.3.1. Tipos de sismos 30

2.3.2. Parâmetros sismológicos 32

2.3.3. Ondas planas de tensão (elásticas) 34

2.3.4. Análise de estabilidade sob carregamento sísmico 37

2.3.5. Resposta dinâmica de barragem de terra 41

3. MODELAGEM COMPUTACIONAL COM O PROGRAMA ABAQUS 45

3.1.Características gerais do programa 45

$\begin{array}{ll}3.2 \text { Arquivo de entrada de dados } & 47\end{array}$

3.3 Aspectos da análise sísmica com ABAQUS 48

4. ANÁLISE NUMÉRICA DA BARRAGEM DE TERRA DE POMACOCHA 52

4.1. Características da barragem de Pomacocha 52

4.1.1. Fundação 53

4.1.2. Núcleo da barragem existente 53

4.1.3. Espaldares da barragem existente 53

4.1.4. Corpo da barragem projetada 54

4.2. Modelagem da construção da barragem projetada 54

4.3. Modelagem do primeiro enchimento do reservatório da barragem $\begin{array}{ll}\text { projetada } & 64\end{array}$

4.4. Modelagem do comportamento sísmico $\quad 75$ 
5. CONCLUSÖES

REFERÊNCIA BIBLIOGRÁFICA

87

APÊNDICE A

97

APÊNDICE B 


\section{Lista de Figuras}

Figura 2.1. Esquema de construção incremental de um aterro de grande extensão 20

Figura 2.2. Distribuição de recalque com a altura do aterro (Parra,1996) 21

Figura 2.3 Tensões principais máximas perto da base do núcleo para diferentes relações entre os módulos de elasticidade do núcleo e do espaldar (apud Law 1975)

Figura 2.4 Recalque máximo no centro do núcleo para diferentes relações entre os módulos de elasticidade do núcleo e do espaldar (apud Law 1975)

Figura 2.5 Trajetórias de tensão durante a fase de construção (apud Naylor 1991)

Figura 2.6 Efeitos do primeiro enchimento do reservatório em uma barragem zonada (Nobari e Duncan, 1972)

Figura 2.7 Trajetórias de tensão típicas no material de enrocamento (Veiga Pinto, 1983)

Figura 2.8 Trajetórias de tensão típicas no material do núcleo central (Veiga Pinto, 1983)

Figura 2.9 O continente universal Pangea, segundo Wegener (1912).

(a)Há 200 milhões de anos. (b) há 150 milhões de anos. (c) há 1 milhão de anos

Figura 2.10 Efeitos de subducção entre duas placas contíguas 32

Figura 2.11 Um acelerograma e sus principais características

Figura 2.12 Diferentes tipos de ondas planas de tensão em material Sólido

Figura 2.13 Registro de ondas sísmicas

Figura 2.14 Ondas sísmicas registradas a $10.000 \mathrm{Km}$ do epicentro:

(a)Sismo de foco profundo; (b) Sismo de foco superficial conforme Sauter, 1988) 
Figura 2.15 Integração no tempo do registro de aceleração para determinação de velocidades e deslocamentos $\quad 40$

Figura 2.16 Determinação de ameaça sísmica por método deterministico 42

Figura 3.1 Módulos Gerais do Programa ABAQUS 45

Figura 3.2 Diagrama de blocos para simulações com o programa ABAQUS(V 6.3)

Figura 4.1 Localização da barragem de Pomacocha na Província de JuninPeru

Figura 4.2 Seção transversal da barragem atual de Pomacocha e de sua expansão projetada em 1996

Figura 4.3 Simulação da construção incremental da barragem de Pomacocha: cinco camadas iniciais na barragem existente e dez camadas Subseqüentes na barragem projetada

Figura 4.4 Malha de elementos finitos utilizada para análise da construção da barragem de Pomacocha

Figura 4.5 Distribuição das tensões verticais na construção da barragem projetada de Pomacocha após lançamento da terceira, sexta y décima camadas de aterro.

Figura 4.6 Distribuição das tensões horizontais na construção da barragem projetada de Pomacocha após lançamentos da terceira, sexta e décima camadas de aterro

Figura 4.7 Distribuição das tensões cisalhantes na construção da barragem projetada de Pomacocha após lançamentos da terceira, sexta,e décima camadas de aterro

Figura 4.8 Distribuição dos deslocamentos verticais na construção da barragem projetada de Pomacocha após lançamentos da terceira, sexta e décima camadas de aterro

Figura 4.9 Distribuição dos deslocamentos horizontais na construção da barragem projetada de Pomacocha após lançamento de terceira, sexta e décima camadas de aterro.

Figura 4.10 Distribuição das tensões verticais na barragem projetada de Pomacocha após os estágios 3, 6, 9 do primeiro enchimento do reservatório.

Figura 4.11 Distribuição das tensões horizontais na barragem projetada de Pomacocha após estágios 3, 6 e 9 do primeiro enchimento do reservatório. 
Figura 4.12 Distribuição das tensões cisalhantes na barragem projetada de Pomacocha após estágios 3, 6, e 9 do primeiro enchimento do reservatório

Figura 4.13 Distribuição dos deslocamentos verticais na barragem projetada de Pomacocha após os estágios 3, 6, e 9 do primeiro enchimento do reservatório.

Figura 4.14 Distribuição dos deslocamentos horizontais na barragem projetada de Pomacocha após estágios 3, 6, e 9 do primeiro enchimento do reservatório

Figura 4.15 Alguns pontos nodais e elementos da malha utilizada na análise numérica

Figura 4.16 Historia de recalque dos pontos nodais 617 (crista) e 110(centro da barragem) durante o período de construção e primeiro enchimento do reservatório

Figura 4.17 Historia dos deslocamentos horizontais dos pontos nodais 617 (crista) e 110 (centro da barragem) durante o período de construção e enchimento do reservatório.

Figura 4.18 Componentes horizontais da deformação normal elástica (em marron) e plática (em verde) avaliadas no centróide do elemento 218 da figura 4.15

Figura 4.19 Componente horizontal de deformação normal elástica (em marron) e plástica (em verde) avaliadas no centróide do elemento 196 da figura 4.15

Figura 4.20 Componente horizontal da deformação normal elástica (em marron) e plástica (em verde) avaliadas no centróide do elemento 216 da figura 4.15

Figura 4.21 História das tensões horizontais (em marron) e vertical (em verde) no centróide do elemento 218 da figura 4.15.

Figura 4.22 História das tensões horizontais (em marron) e vertical (em verde) no centróide do elemento 196 da figura 4.15.

Figura 4.23 História das tensões horizontal (em marron) e vertical (em verde) no centróide do elemento 216 da figura 4.15.

Figura 4.24 Mapa de isoaceleracões para a zona da barragem de Pomacocha, Peru

Figura 4.25 Acelerograma utilizado na analise. 
Figura 4.26 Distribuição das tensões verticais durante a excitação

sísmica na barragem de Pomacocha, nos tempos $\mathrm{t}=12.58 \mathrm{~s}$ e $\mathrm{t}=19.80 \mathrm{~s}$.

Figura 4.27 Distribuição das tensões horizontais durante a excitação

sísmica na barragem de Pomacocha, nos tempos $t=12.58 \mathrm{~s}$ e $\mathrm{t}=19.80 \mathrm{~s}$.

Figura 4.28 Distribuição das tensões cisalhantes durante a excitação

sísmica na barragem de Pomacocha, nos tempos $\mathrm{t}=12.58 \mathrm{~s}$ e $\mathrm{t}=19.80 \mathrm{~s}$.

Figura 4.29 Distribuição dos deslocamento verticais durante a excitação sísmica na barragem de Pomacocha, nos tempos $t=12.58 \mathrm{~s}$ e $\mathrm{t}=19.80 \mathrm{~s}$.

Figura 4.30 Distribuição dos deslocamentos horizontais durante a excitação sísmica na barragem de Pomacocha, nos tempos $\mathrm{t}=12.58 \mathrm{~s}$ e $\mathrm{t}=19.80 \mathrm{~s}$.

Figura 4.31 História das acelerações horizontais (a) na fundação nó 353;

(b) no centro da barragem nó 110; (c) na crista nó 617

Figura 4.32 História das deformações horizontais elásticas (em marron)

e plástica (em verde) para o centróide do elemento 218 da

figura 4.15

83

Figura 4.33 História das deformações horizontais elástica (em marron) e plástica (em verde) para o centróide do elemento 196 da figura 4.15

Figura 4.34 História das deformações horizontais elásticas (em marron) e plástica (em verde) para o centróide do elemento 216 da figura 4.15 . 


\section{Lista de Tabelas}

Tabela 2.1. Relações de escada entre protótipo e modelo (Seco Pinto, 1993) 38

Tabela 4.1 Parâmetros de resistência ao cisalhamento no solo de fundação 53

Tabela 4.2 Parâmetros de resistência ao cisalhamento no núcleo da barragem existente

Tabela 4.3 Parâmetros de resistência no solo dos espaldares da barragem existente

Tabela 4.4 Parâmetros de resistência ao cisalhamento no corpo da barragem projetada

Tabela 4.5 Valores representativos de critérios de projeto considerando movimentos sísmicos

Tabela A1 - Comparação dos valores de tensão obtidos com os programas Plaxis e ABAQUS ao final do estágio de construção.

Tabela A2 - Comparação dos valores de deslocamento obtidos com os programas Plaxis e ABAQUS ao final do estágio de construção. 


\section{Lista de Símbolos}

A Amplitude máxima do sismo

[C] Matriz de amortecimento

[K] Matriz de rigidez

D Módulo de compressão confinada

E Módulo de elasticidade (módulo de Young)

$\mathrm{E}_{h} \quad$ Módulo de elasticidade na direção horizontal

$\mathrm{E}_{v} \quad$ Módulo de elasticidade na direção vertical

g Aceleração da gravidade

G Módulo de cisalhamento

$\mathrm{H} \quad$ Altura total do aterro

h Altura de uma camada existente

[M] Matriz de massa

$\{P\} \quad$ Vetor global dos carregamentos nodais

p Tensão normal octaédrica total

p' Tensão normal octaédrica efetiva

q Tensão desviadora

$\{u\}$ Deslocamentos nodais

$\{\dot{u}\} \quad$ Velocidades nodais

$\{\ddot{u}\} \quad$ Acelerações nodais

$u \quad$ Deslocamento vertical máximo

$\mathrm{V}_{p} \quad$ Velocidade da onda $\mathrm{P}$

$\mathrm{V}_{r} \quad$ Velocidade da onda $\mathrm{R}$

$\mathrm{V}_{s} \quad$ Velocidade da onda S

$\Delta \sigma_{z z} \quad$ Acréscimo de tensão vertical

$\sigma_{1} \quad$ Tensão principal maior

$\sigma_{3} \quad$ Tensão principal menor 
$\sigma_{1 \max } \quad$ Máxima tensão principal

$\gamma \quad$ Peso especifico do material

$v \quad$ Coeficiente de Poisson

Outros símbolos definidos no texto deste trabalho. 